\title{
A "DERROTA DA LEI DE SAY" ELEMENTOS TEÓRICOS FUNDAMENTAIS E ALGUMAS IMPLICAÇÕES METODOLÓGICAS E DINÂMICAS*
}

\section{Ricardo Ramalhete Moreira ${ }^{* *}$}

\begin{abstract}
RESUMO A refutação da Lei de Say pela Teoria Geral (TG) de Keynes está apoiada, basicamente, sobre dois elementos: a incerteza é necessária, mas não suficiente. A refutação completa daquela lei depende também de um ativo que possua as propriedades essenciais descritas e analisadas pela TG. Incerteza e moeda (enquanto ativo líquido) permitem à economia um equilíbrio com desemprego involuntário. Destarte, a política econômica possui um papel lógico na economia e a análise econômica ganha novos elementos metodológicos e dinâmicos. Abre-se espaço para a instabilidade e a irreversibilidade na teoria econômica. Este artigo abrange essas considerações, a partir de uma abordagem pós-keynesiana.
\end{abstract}

Palavras-chave: Lei de Say; Keynes; incerteza; instabilidade; irreversibilidade Código JEL: B41; D81; E12

\section{THE "DEFEAT OF THE LAW OF SAY": BASIC THEORICAL ELEMENTS AND SOME METHODOLOGICAL AND DYNAMIC IMPLICATIONS}

ABSTRACT Fundamentally, the refutation of Say's Law by Keynes' General Theory (GT) depends on two elements: the uncertainty is necessary, but not enough. The full refutation of that law also depends on an asset which has the essential properties described and analyzed by GT. Uncertainty and money (as a liquid asset) allow the system an equilibrium with involuntary unemployment. Therefore, economic policy has a logical role on the system and economic analysis receives new methodological and dynamic elements. Instability and irrevocability reach place in economic theory. This article regards these considerations, from a post-keynesian perspective.

Key words: Say's Law; Keynes; uncertainty; instability; irrevocability

* Artigo recebido em 10 de agosto de 2004 e aprovado em 12 de maio de 2005.

** Professor do Departamento de Economia da UFES, mestrando em Economia (UFES), e-mail: ramalhete.s@uol.com.br 


\section{INTRODUÇÃO}

A noção de que "a oferta cria sua própria demanda", a Lei de Say, baseia-se na hipótese de que todos os rendimentos gerados no processo de produção são canalizados para a compra de bens e serviços produzidos pela indústria. Nesta economia idealizada, o excedente da renda sobre o consumo é convertido, necessariamente, em investimentos, sendo a taxa de juros a responsável pela igualação entre poupança e investimento. Sendo o comportamento dos fenômenos econômicos visto como predeterminado (axioma da ergodicidade), os mercados são assumidos como hábeis em transmitir aos empresários toda a informação necessária para que o pleno emprego, sem impedimentos, seja alcançado. Ademais, a moeda torna-se um mero facilitador das trocas mercantis.

Os fundamentos teóricos lançados pela Teoria Geral (1936) de Keynes impedem o funcionamento da Lei de Say? Não tendo caráter exaustivo, o presente trabalho será centrado na resposta a esta pergunta, mediante a noção de uma economia monetária de produção, ou empresarial. Os conceitos de incerteza e de moeda, como reserva de valor, formam um todo eficaz na refutação da Lei de Say.

A incerteza (em vez do risco), aliada à existência de ativos líquidos, permite que parte da renda não se transforme em demanda efetiva, esta sim, geradora de emprego. $\mathrm{Na}$ impossibilidade de o próprio sistema, deixado à própria "sorte", caminhar em direção ao pleno emprego, a presença do Estado - como um elemento estimulador das expectativas e dos investimentos - surge de maneira coerente. Dito isto, a própria análise econômica recebe novos elementos metodológicos e dinâmicos. O presente artigo pretende abranger essas considerações, a partir de uma abordagem pós-keynesiana.

A discussão levantada neste artigo não visa meramente relembrar um tema importante na história do pensamento econômico. Isto porque, em certo sentido, as mesmas questões permanecem, ainda que sob outra roupagem, nas teorias macroeconômicas contemporâneas. Em especial, a escola das expectativas racionais caracteriza-se pelo uso da hipótese da ergodicidade e da neutralidade da moeda. Por outro lado, a corrente pós-keynesiana busca reconstruir o pensamento de Keynes, a partir das propriedades essenciais da moeda e da incerteza não mensurável (incerteza forte). 
Na seção 1 será analisado o funcionamento de uma economia fundada na Lei de Say; na seção 2, a noção de economia monetária de produção é fornecida, assim como a função das expectativas e da incerteza nesse contexto; na seção 3, por sua vez, as propriedades essenciais da moeda, uma vez consideradas, prometem o "fechamento" da refutação teórica da Lei de Say; a seção 4 mostra, brevemente, como o Estado ativo surge de maneira coerente no pensamento keynesiano, ao passo que a seção 5 descreve algumas implicações metodológicas e dinâmicas derivadas da TG; seguem-se as considerações finais.

\section{QUANDO TODAS AS COISAS CONVERGEM PARA O MELHOR DOS MUNDOS: A LEI DE SAY}

A análise da determinação da renda e do emprego feita pelos economistas neoclássicos ${ }^{1}$ pode ser descrita a partir da chamada Lei de Say. Esta se baseia em mostrar que toda renda criada no processo de produção, na forma de rendimentos pagos aos fatores, retorna ao sistema sob a forma de gastos com os bens produzidos pelo sistema produtivo. O fluxo "real" de bens e serviços tem sua contrapartida no fluxo "monetário" de renda (Kregel, 1980, p. 33). Assim, ao contrário do que muitos contemporâneos de Say diziam, torna-se impossível haver crises permanentes de superprodução, ou de insuficiência de demanda, uma vez que quando qualquer unidade de um bem é produzida, este ato aumenta a oferta e a demanda na mesma proporção (Hagen, 1949, p. 4). A conservação da renda na Lei de Say expressa, na economia, o que a primeira lei da termodinâmica expressa na física, ou seja, a conservação de energia nos sistema estáveis (Herscovici, 2003).

Uma economia regida pela Lei de Say pode ser vista como uma economia "neutra", no sentido de que sempre será satisfeita a seguinte igualdade: gastos correntes $=$ produto corrente $=$ renda corrente. Para que isto ocorra é preciso que a totalidade dos rendimentos gerados na produção seja convertida em gastos com os bens produzidos, não podendo haver jamais deficiência de demanda, nem obstáculos ao pleno emprego. Esta concepção de economia foi descrita por Keynes: a Lei de Say equivale à proposição de que não há impedimentos ao pleno emprego, porque para qualquer nível de emprego, sempre, o preço da demanda agregada será equivalente ao preço da oferta agregada (Keynes, 1936, p. 39). 
Sendo $Z$ a oferta agregada e $D$ a demanda agregada, a afirmação de que "a oferta cria sua própria demanda" significa que

$f(N)$ e $\phi(N)$ são iguais para todos os valores de $N$, isto é, para qualquer volume de produção e de emprego; e que, quando há um aumento em $Z$ [ $=\phi$ $(N)]$ correspondente a um aumento em $N, D[=f(N)]$ aumenta necessariamente na mesma quantidade que $Z$. (Keynes, op. cit., p. 39)

A Lei de Say implica uma economia onde a moeda é "neutra". Nas palavras do próprio economista francês,

Nos lugares que produzem muito, cria-se a única substância com a qual se pode comprar: refiro-me ao valor. O dinheiro representa apenas um ofício passageiro nessa troca dupla; e, terminadas as trocas, verifica-se sempre: produtos foram pagos com produtos. (...) Os produtos criados fazem nascer demandas diversas. (Say, 1803, p. 139 e 142) ${ }^{2}$

O entendimento do motivo pelo qual, em uma economia regida pela Lei de Say, a oferta agregada sempre equivale à demanda agregada requer uma análise do papel da taxa de juros na teoria neoclássica. A taxa de juros surge aqui como uma força determinante para o equilíbrio macroeconômico, uma vez que é ela a responsável por igualar o montante de poupança com o montante de investimento. Caso, para qualquer nível de emprego, haja uma diferença entre poupança e investimento, "the interest rate mechanism can be expected to equilibrate the flows of savings and investment, and by doing so to insure that there will be demand for the aggregate output of the economic system, no matter how large" (Hagen, 1949, p. 10). Por exemplo: se a poupança for superior ao investimento $(S>I)^{3}$ e, portanto, a oferta agregada for superior à demanda agregada, as instituições financeiras tendem a reduzir a taxa de juros, pois não lhes faz sentido permanecer com recursos ociosos. Assim, a taxa de juros é diminuída, aumentando o investimento e reduzindo a poupança, até o ponto em que $S=I$, onde novamente a oferta é igual à demanda. Em uma "economia da Lei de Say" qualquer desvio em relação ao pleno emprego é apenas provisório. Segundo Keynes, “o nível de emprego está em equilíbrio neutro sempre que $N$ seja inferior ao seu valor máximo, de modo que se possa esperar que as forças da concorrência entre os empresários o elevem até esse máximo. Apenas neste ponto, segundo a teoria clássica, pode haver um equilíbrio estável” (Keynes, 1936, p. 41). 
A única forma de a Lei de Say ser válida em uma economia onde salários são pagos em moeda é fazendo com que $Z-D_{1}{ }^{W}=D_{2}{ }^{W}$ para qualquer nível de emprego, onde $D_{1}{ }^{W}$ são os gastos em consumo, e $D_{2}{ }^{W}$, os gastos em bens de capital, ambos medidos em unidades de salários. Para que a oferta agregada $(Z)$ sempre seja igual à demanda agregada $\left(D=D_{1}{ }^{W}+D_{2}{ }^{W}\right)$, o hiato entre $Z$ e $D_{1}{ }^{W}$ - que cresce com o aumento do emprego (Keynes, op. cit., p. 41) —, expressando os recursos não gastos em consumo, deve ser igual aos gastos com bens de investimento $\left(D_{2}{ }^{W}\right)$ (Davidson, 1999, p. 53).

O objetivo de Keynes, com sua Teoria Geral, era demonstrar que não existe tendência alguma para se esperar uma igualdade entre $Z[=\phi(N)] \mathrm{e}$ $D[=f(N)]$ para qualquer nível de emprego, como sustentado pela Lei de Say. Portanto, era necessário mostrar que os gastos correntes poderiam ser distintos da renda, de tal forma que, em caso de os gastos serem menores que aquela, p. ex., não podendo cobrir seus custos de produção com as receitas derivadas das vendas presentes, os empresários fossem forçados a reduzir sua produção e, da mesma maneira, o nível de emprego (Kregel, 1980, p. 34). Entretanto, antes de se buscar entender o motivo por que é possível haver um desvio dos gastos correntes em relação à renda corrente - o que leva à consideração do papel da incerteza e da moeda na economia - , convém tecer um breve comentário acerca de uma das hipóteses por trás do funcionamento da economia neoclássica: o axioma da ergodicidade.

Esse axioma implica a possibilidade de conhecimento dos eventos futuros, mediante estimação estatística, a partir das informações passadas e presentes coletadas via sistema de preços (Davidson, 1999, p. 55). Um mundo onde haja ergodicidade não pode possuir incerteza (Filho e Araújo, 2000, p. 4). Isto se traduz na possibilidade de os preços transmitirem para os agentes, de forma gratuita, toda informação relevante dispersa no mercado (Herscovici, 2002b, p. 58). ${ }^{4}$

Por assumir que a atividade econômica ocorra sob condições de certeza acerca dos eventos futuros, os economistas neoclássicos presumiam que os agentes tinham conhecimento perfeito de uma realidade econômica programada e imutável, a qual governaria todos os eventos passados, presentes e futuros. Neste sentido, uma economia segundo os axiomas neoclássicos está sujeita à invariabilidade, ${ }^{5}$ ou seja, não é suscetível de sofrer mudanças induzidas pela ação humana (Davidson, 1996, p. 479). 
Somente com base no axioma da ergodicidade, ainda que de forma implícita, pode-se chegar aos resultados de uma economia "neutra". Partindo do equilíbrio $Z=D$, uma redução do consumo não possui, ao menos expost, impacto sobre o emprego agregado, ${ }^{6}$ uma vez que o resultante aumento da poupança $\left(Z-D_{1}{ }^{W}\right)$, dado o investimento corrente $\left(D_{2}{ }^{W}\right)$, na economia neoclássica implica uma redução da taxa de juros. Esta sinalização informa aos empresários que a sociedade optou por maior consumo no futuro, e a elevação do investimento será exatamente a necessária para viabilizar a elevação da capacidade produtiva "requerida" pela sociedade. Sendo a realidade ergódica, a taxa de juros informa como uma variação no consumo presente é traduzida na variação do consumo futuro. Em uma versão neoclássica, o consumidor realiza uma escolha entre consumo presente e futuro, estando diante de sua restrição orçamentária intertemporal. Ele otimiza sua utilidade total quando sua curva de indiferença (entre consumo presente e futuro) tangencia sua restrição orçamentária intertemporal. ${ }^{7}$ Evidentemente, neste caso, o consumidor possui plena certeza acerca de sua função-objetivo, sendo a posse de moeda uma escolha irracional.

No capítulo 14 de sua Teoria Geral, Keynes entra em maiores detalhes sobre a determinação e a natureza da taxa de juros na teoria neoclássica. O erro básico dessa teoria estaria em considerar a taxa de juros como a recompensa pela espera, ou pela renúncia ao consumo presente, em vez de considerá-la, como fez o próprio Keynes, como a recompensa pelo não-entesouramento de moeda. Keynes rompe de duas maneiras com a concepção neoclássica sobre a taxa de juros: (a) ao atribuir a responsabilidade pela determinação dessa taxa não à poupança e investimento, mas à oferta monetária e preferência pela liquidez; (b) ao reconhecer de forma efetiva a correlação positiva entre investimento e nível de renda, o que não era aceito pela teoria neoclássica; nesta, uma variação do investimento é acompanhada de uma variação da poupança, via sinalização dos juros, de tal maneira que a renda permanece constante, assim como a identidade entre poupança e investimento é preservada (Keynes, 1936, capítulo 14).

Por outro lado, uma vez que a realidade não seja ergódica, as coisas mudam de natureza. Em Keynes, como não é adotado o axioma da ergodicidade e os mercados nada podem informar sobre o futuro, não há a falácia de que a redução no consumo presente informe um aumento no consumo 
futuro (Kregel, 1980, p. 36). Os neoclássicos, por sua vez, não precisavam se importar com o realismo de suas hipóteses, pois estavam dispostos a construir um sistema lógico completo, muito mais do que a responder a questões de política (Dow, 1985, p. 52).

\section{UMA ECONOMIA MONETÁRIA DE PRODUÇÃO (OU EMPRESARIAL): RESULTADOS ESPERADOS}

Em uma economia monetária de produção, ao contrário do que ocorre em uma economia "neutra", parte da renda gerada no processo produtivo pode não ser convertida em gastos correntes. Nessa economia, a razão gastos/ renda pode ser diferente de 1. Flutuações nesta razão podem causar flutuações na renda corrente, na demanda efetiva e, portanto, no nível de emprego (Kregel, 1980, p. 34).

A Teoria Geral (1936) de Keynes pretendia abranger a análise econômica em quaisquer níveis de emprego, e não somente no caso particular em que há pleno emprego. Por este motivo, Keynes inicia a apresentação do princípio da demanda efetiva mostrando que o volume de emprego depende da soma de duas categorias de despesas: $D_{1}{ }^{W}$, os gastos em consumo, e $D_{2}{ }^{W}$, os gastos em investimento $\left[D=D_{1}{ }^{W}+D_{2}{ }^{W}\right.$ é o que se chama demanda efetiva em Keynes (1936, p. 41)]. Enquanto $D_{1}{ }^{W}$ representa as despesas relacionadas à renda corrente, $D_{2}{ }^{W}$ representa as despesas não relacionadas à mesma. Davidson (1999) define a teoria neoclássica como o caso particular em que $\mathrm{D}_{2}{ }^{W}=0$, e assim, a demanda efetiva depende apenas do nível de emprego e de renda corrente.

Quando $D_{2}{ }^{W}$ não fosse uma categoria nula $\left(D_{2}{ }^{W}>0\right)$,

Keynes tinha ainda que demonstrar que este tipo de gasto não era relacionado à renda corrente e ao emprego, [...]. Ao contrário, as despesas de investimento dependem das expectativas exógenas dos empresários. ${ }^{8}$ (Davidson, 1999, p. 53)

Logo, $D_{2}{ }^{W} \neq g(N)$, ou seja, os investimentos não são função do emprego e renda correntes, tanto no curto como no longo prazo.

O fato de os investimentos serem determinados pelos rendimentos esperados de longo prazo, uma vez que a decisão de investir tomada hoje implica produzir para vendas futuras, explica, em parte, ${ }^{9}$ as possíveis diferenças 
entre os gastos correntes e a renda agregada. Em uma economia empresarial, parte da renda gerada na produção pode "vazar” para fora do fluxo idealizado por Say, uma vez que a poupança, o excedente da renda sobre os gastos em consumo, não pode sinalizar aos empresários como e quando ela própria será utilizada no futuro. Assim, sob condições de incerteza, os empresários tomam suas decisões baseados em expectativas acerca dos resultados esperados (lucros) ao longo da vida útil dos ativos produtivos. Os resultados presentes afetam as decisões dos empresários apenas na medida em que, primeiro, afetam suas expectativas acerca dos resultados esperados (Kregel, 1980, p. 35).

Na medida em que, em uma economia não sujeita à Lei de Say, a renda e o emprego são determinados, ao menos em parte, por uma categoria de gastos não relacionada aos rendimentos correntes, as expectativas do empresariado surgem como fator de fundamental relevância. A questão, todavia, é que o cálculo das rendas esperadas para um bem de capital qualquer é feito como sobre "areia movediça", ou seja,

o fator de maior importância é a extrema precariedade da base do conhecimento sobre o qual temos de fazer os nossos cálculos das rendas esperadas. O nosso conhecimento dos fatores que regularão a renda de um investimento alguns anos mais tarde é, em geral, muito limitado e, freqüentemente, desprezível. (Keynes, 1936, p. 125)

Uma economia monetária de produção assume a presença da incerteza sob a qual grande parte das decisões é tomada, rejeitando a hipótese neoclássica da ergodicidade. Quando os agentes econômicos são concebidos como conscientes de sua incerteza sobre eventos futuros, os resultados derivados do axioma da ergodicidade não podem ocorrer. Os sinais passados e presentes, extraídos do mercado, não fornecem informações seguras sobre o que lhes aguarda no futuro (Davidson, 1999, p. 53).

A concepção de incerteza é algo relevante na Teoria Geral (1936) de Keynes. Dequech (1999) busca defender uma concepção de incerteza "num sentido forte". Nas situações em que os agentes podem definir uma distribuição de probabilidade para todos os eventos possíveis, há risco ("incerteza fraca”). A “incerteza forte” estaria associada às situações nas quais é impossível formar, de maneira confiável, probabilidades numéricas para os eventos futuros. Neste caso, faltam "evidências” ou informações necessárias 
para tal tarefa (Dequech, 1999, p. 91). A incerteza que povoa a natureza econômica é causada não pela simples incapacidade de os agentes coletarem e processarem todas as informações disponíveis, mas pelo fato de que as informações necessárias não existem no momento da tomada de decisão: tal informação existirá apenas no futuro, que, por sua vez, ainda será criado pelos agentes (Dequech, 2001). ${ }^{10}$ Destarte, “incerteza forte" significa que o futuro é, a rigor, impossível de ser conhecido (Feijó, 1999, p. 111).

Portanto, em uma economia empresarial, onde há incerteza em vez de risco probabilístico, o mecanismo auto-regulador da Lei de Say - que une decisões presentes às decisões futuras - não possui espaço. A decisão de poupar, restringindo o consumo presente, forma um único sinal corrente aos empresários: diminuição nas receitas de vendas. Entretanto, nada informa sobre o que será consumido no futuro, pois os próprios consumidores não o sabem (Kregel, 1980, p. 37). Na inexistência de evidências sobre o futuro, empresários formam expectativas sensíveis aos resultados presentes, pois estes últimos afetam o que se espera dos resultados futuros. Supõe-se que "a situação existente dos negócios continuará por tempo indefinido, a não ser que tenhamos razões concretas para esperar uma mudança" (Keynes, 1936, p. 126). Paradoxalmente, essas "razões concretas", na ausência de informação sobre o futuro, apenas podem advir de mudanças na própria situação existente dos negócios.

Dito isso, nota-se uma inversão de lógica a partir do pensamento de Keynes: enquanto na teoria neoclássica a redução do consumo presente implica um aumento dos investimentos, via sinalização dos mercados (redução da taxa de juros), na Teoria Geral, por sua vez, a redução do consumo corrente pode deprimir o nível de investimento, por seu efeito negativo sobre as expectativas e, assim, sobre o cálculo das rendas esperadas.

Caso as expectativas de curto prazo não sejam realizadas, as expectativas de longo prazo podem sofrer alterações. Se a sociedade consome menos no presente, não há razões para pensar que ela consumirá mais no futuro. Assim, dado o estoque de capital corrente, uma frustração das expectativas tem implicações sobre o montante que os empresários desejam investir em aumento daquele estoque. Isto anula qualquer posição estática de longo prazo, permitindo a existência de flutuações econômicas endógenas ${ }^{11}$ (Herscovici, 2002a, p. 73). 
Herscovici (2003) apresenta uma formalização do mecanismo pelo qual as flutuações econômicas, a partir dos elementos fornecidos pela TG, têm uma origem endógena: Keynes teria deixado claro que o investimento é uma função do diferencial da eficiência marginal do capital em relação à taxa de juros, enquanto a eficiência marginal do capital, por sua vez, teria uma relação inversa com o montante de investimentos. ${ }^{12}$ Keynes supõe a existência de rendimentos decrescentes na indústria, dado que a tecnologia é tomada como constante. Assim, explica-se a inclinação positiva da curva de oferta agregada $(Z)$ com base em que (i) os rendimentos decrescentes se expressam no fato de que o produto cresce proporcionalmente menos que $o$ nível de emprego; (ii) portanto, a fim de que os lucros sejam maximizados, as receitas previstas têm de crescer proporcionalmente mais do que o emprego de fatores (Herscovici, 2004, p. 4). De maneira geral, tem-se que:

(1) $I=\varphi_{1}(e-i)$

(2) $e=\varphi_{2} I$

(3) $e=\varphi_{2} \cdot\left[\varphi_{1}(e-i)\right]$

Sendo: $I$ = investimento; $e$ = eficiência marginal do capital; $i=$ taxa de juros (exógena); $\varphi_{1}>0 ; \varphi_{2}<0$.

Desta maneira, um período de expansão dos investimentos, dada a taxa de juros, gera uma paralela redução na eficiência marginal do capital, impedindo que o investimento se mantenha em níveis elevados. Portanto, "essas variações constituem um mecanismo que fornece uma explicação endógena das flutuações e da inversão de tendência" (Herscovici, 2003, p. 10). A equação (3), resultante da combinação de (1) e (2), mostra que a eficiência marginal do capital está inversamente relacionada com o seu próprio diferencial em relação à taxa de juros. ${ }^{13}$

Vale ainda um comentário sobre a questão da poupança na Teoria Geral. Nesta, a poupança torna-se um simples resíduo. Em Keynes, poupança e investimento são equivalentes, e a primeira perde a importância enquanto meio de financiamento para o segundo: o investimento, através do multiplicador, altera a renda no sentido de proporcionar a poupança que o financia. A igualdade entre poupança e investimento na Teoria Geral não é alcançada via taxa de juros, mas através das variações da renda, induzidas por 
mudanças no investimento, ou seja, "uma vez alterado o investimento, a escala em que a renda variará será menor ou maior de acordo com a propensão a consumir, mas necessariamente o suficiente para que seu resíduo, após se descontar o consumo observado, seja igual ao investimento" (Meirelles, 1998, p. 106).

Muito embora a existência de incerteza seja um elemento necessário para a refutação da Lei de Say, esse elemento não é suficiente. É preciso também fazer uma consideração das características essenciais da moeda.

\section{A CONCEPÇÃO KEYNESIANA DE TAXA DE JUROS E MOEDA}

O que permite flutuações na razão gastos/renda em uma economia monetária de produção, na qual as decisões de investimento são tomadas sob condições de incerteza, é a existência de uma reserva de valor que preserva poder de compra ao longo do tempo. Uma vez que qualquer ativo durável tem a capacidade de existir ao longo do tempo, Keynes queria mostrar que os indivíduos desejam saber qual dos ativos lhes dará o melhor retorno prospectivo (Kregel, 1980, p. 38-41).

Keynes definiu três atributos que os diversos bens duráveis possuem: (i) o rendimento obtido com o uso do ativo ao longo do tempo (q); (ii) os custos de manutenção do ativo (c); (iii) o prêmio de liquidez (l), obtido com a posse do ativo, medido pelo montante que as pessoas estão dispostas a pagar, em termos do próprio bem, pela segurança potencial derivada de sua posse. Assim, o retorno prospectivo de qualquer ativo durável, em termos de si mesmo, pode ser medido pela soma $[(q-c)+1]^{14}$ (Keynes, 1936, p. 177-178). Os bens cujo preço de oferta é inferior ao preço de demanda são objeto de nova produção, uma vez que $[(q-c)+1]$ mostra-se elevado em relação aos outros. Todavia, Keynes notou que o retorno prospectivo dos ativos duráveis não monetários é inversamente relacionado com a demanda pelos mesmos, ou seja, "à medida que aumenta o estoque de bens cuja eficiência marginal era, a princípio, pelo menos igual à taxa de juros, essa eficiência marginal tende a baixar" (Keynes, 1936, p. 179).

Esse processo tenderia, a priori, ao ponto em que $[(q-c)+1]$ fosse igual para todos os bens duráveis, situação esta equivalente ao equilíbrio estável em que nenhum investimento adicional apresenta vantagem sobre os de- 
mais. Contudo, a existência da moeda, dadas suas características especiais, impede que aquela equalização das eficiências marginais ocorra, como implícito na teoria neoclássica, apenas no pleno emprego. Isto porque o retorno prospectivo da moeda não está nas condições técnicas de sua oferta, mas no seu prêmio de liquidez. Esse prêmio não depende da quantidade de moeda ofertada, porém da psicologia do público, expressa na preferência pela liquidez (Kregel, 1980, p. 41-42). Havendo um ativo cuja taxa de juros decline mais lentamente que as eficiências marginais de bens de capital, pode haver um "stop" aos investimentos antes que ocorra o pleno emprego (Keynes, 1936, p. 184-185).

Em uma economia onde há incerteza, a moeda surge como a reserva de valor por excelência, dado seu prêmio de liquidez. Parte da renda gerada na produção pode ser usada para reter moeda, em vez de converter-se em demanda efetiva (que gera emprego). A taxa de juros, determinada pela relação entre oferta monetária (exógena) e preferência pela liquidez, não apresenta, assim, uma tendência de queda, como proposto pela teoria neoclássica, sempre que o consumo presente diminua. Pelo contrário, a redução do consumo corrente, quando decorrente de maior preferência por liquidez, pode elevar a taxa de juros, impedindo novos investimentos cuja eficiência marginal, outrora, era ainda superior à taxa de juros vigente. Por outro lado, a retração das vendas presentes influencia as expectativas dos empresários, que passam a esperar menos vendas futuras, também contribuindo para a diminuição dos investimentos.

Afinal, o que faz da moeda, dentre todos os ativos duráveis existentes, um ativo mais adequado enquanto recipiente de liquidez? E o que faz com que a demanda por moeda impeça a ocorrência da Lei de Say?

Para Keynes, a moeda possui duas propriedades essenciais (Keynes, 1936, p. 180-185):

- Sua elasticidade de produção é, se não nula, muito baixa: "todos os ativos líquidos são não produzíveis pelo uso de trabalho no setor privado" (Davidson, 1999, p. 54). Logo, o aumento da demanda por moeda não permite que os trabalhadores desempregados sejam empregados na produção de mais moeda; ${ }^{15}$

- Sua elasticidade de substituição também é, se não nula, desprezível. Isto significa que, mesmo que o valor de troca da moeda cresça, não sur- 
ge qualquer tendência para substituí-la por outro ativo produzível por trabalho. Não existe, portanto, substituição bruta significativa entre ativos líquidos não produzíveis e os produtos do trabalho na indústria (Davidson, op. cit., p. 54).

Enquanto os detentores de riqueza desejam conservá-la sob a forma de ativos líquidos cujas elasticidades de produção e substituição são quase nulas, o equilíbrio sem pleno emprego é possível. Em outras palavras, quando existem outras formas de usar as poupanças além dos ativos produzíveis, pode haver equilíbrio estável ${ }^{16}$ com desemprego involuntário (Davidson, op. cit., p. 55).

Se o aumento na demanda por moeda criasse os mesmos efeitos sobre o emprego que são criados com a elevação da demanda por bens produzíveis, não haveria a refutação plena da Lei de Say, mesmo sob condições de incerteza. Se o aumento no "preço" da moeda sinalizasse aos empresários, sendo possível aumentar o emprego para produzi-la, e, por sua vez, se houvesse um substituto produzível próximo à moeda, de maneira que o aumento no "preço" da última aumentasse a demanda pelo primeiro, então, como na economia "neutra", não haveria impedimentos ao pleno emprego (Kregel, 1980, p. 43).

Por outro lado, dadas as propriedades essenciais da moeda e uma realidade não ergódica, quando as expectativas dos agentes acerca de um futuro próximo ou remoto são pessimistas, o desejo de reter ativos líquidos é aumentado, permitindo a ociosidade de fatores de produção (desemprego involuntário), porque parte da renda corrente "foge" em direção à posse de moeda (Feijó, 1999, p. 111). Segundo Keynes, "os homens não podem encontrar emprego quando o objeto de seus desejos (isto é, o dinheiro) é uma coisa que não se produz e cuja demanda não pode ser facilmente contida" (Keynes, 1936, p. 184).

Embora recentemente muitos autores ligados ao mainstream queiram restringir o desemprego involuntário keynesiano a situações em que não há flexibilidade perfeita dos preços, esta argumentação não parece ser consistente. Em um mundo onde há incerteza, é a existência de certos ativos líquidos (como a moeda) cujas elasticidades de produção e substituição são muito baixas que se constitui na causa do equilíbrio com desemprego. E isto independe da existência de qualquer tipo de rigidez de preços (Davidson, 1999, p. 59). Ou melhor, 
whenever agents believe the future is too uncertain to forecast reliably, they may, even in the long run, desire to postpone their commitment to spend earned claims on current real resources and remain liquid instead, thereby creating a long-term underemployment equilibrium even in the presence of competitive flexprice markets. (Davidson, 1996, p. 502, grifos do autor)

A preferência pela liquidez tem um papel significativo na Teoria Geral. Ela pode ser entendida como uma regra de comportamento dos agentes na busca de melhor alocar sua riqueza sob condições de incerteza. Assim,

sob tal contexto, há preferência por manter parte da riqueza sob forma líquida, monetária, justamente porque a moeda representa a riqueza em forma abstrata, o meio mais geral e flexível de manter poder de compra no tempo e, assim, fazer frente a despesas imprevistas e aproveitar oportunidades lucrativas que sejam aguardadas para um futuro próximo. (Meirelles, 1998, p. 37-38)

\section{HÁ UM LUGAR LÓgICO PARA A POLÍTICA ECONÔMICA A PARTIR DA TEORIA GERAL?}

A política econômica de um governo pode ser orientada por muitas metas sociais. Entretanto, caso sua meta maior seja a de proporcionar ao país uma situação de pleno emprego, ou ao menos uma situação próxima a este, a relevância da própria política econômica dependerá de qual teoria lhe serve como guia.

As implicações da teoria neoclássica para o papel do Estado na economia são claras. Aceitas as hipóteses da ergodicidade e, portanto, da funcionalidade dos preços de mercado como sinalizadores aos empresários (e consumidores), resta pouco espaço para uma política ativa sobre o comportamento da demanda agregada. Neste caso, a ausência de incerteza acerca do futuro torna a moeda um simples numerário e meio de troca; toda a renda gerada no processo de produção é “conservada” no fluxo circular e, assim, a produção encontra uma demanda ideal. As forças endógenas nessa economia não encontram obstáculos ao pleno emprego. Neste ponto, garantido o ótimo social, não restam quaisquer transações lucrativas aos agentes, estando estes em posição maximizadora. Sob uma ótica novo-neoclássica, o desvio da economia de sua trajetória natural apenas ocorre através de choques 
exógenos, tais como aqueles causados por uma alteração da política monetária não antecipada pelos agentes. ${ }^{17}$

É a partir dos elementos teóricos fornecidos pela Teoria Geral que o Estado passa a ter uma função lógica na regulação da demanda agregada. Referindo-se à Lei de Say, Keynes notou que "não sendo esta a verdadeira lei que relaciona a demanda agregada e as funções da oferta, falta ainda escrever um capítulo da teoria econômica, cuja importância é decisiva e sem o qual é inútil qualquer discussão a respeito do volume do emprego agregado" (Keynes, 1936, p. 39). Pode-se afirmar que tal capítulo da teoria econômica foi fornecido ao longo da Teoria Geral.

Em um sistema não ergódico, onde a moeda surge como refúgio diante da incerteza, na presença de um equilíbrio a longo prazo com desemprego, a sociedade pode melhorar a performance da economia, direta ou indiretamente, mediante políticas que favoreçam as expectativas do setor privado e restrinjam sua preferência pela liquidez (Davidson, 1996, p. 503).

Keynes mostrara que o sistema econômico parece apto a repousar sobre situações intermediárias, entre o desemprego total e o pleno emprego, sem apresentar sinais de tendência em direção a um ou outro extremo. Todavia, ele também percebera que a sociedade não precisava se conformar a tais situações: dada a natureza volátil das expectativas empresariais, a instabilidade dos investimentos privados justificava a presença dos investimentos públicos como verdadeiras "injeções de ânimo" na economia (Keynes, 1936, cap. 12 e 18).

Em uma economia monetária de produção, há uma contradição entre o interesse privado e o interesse social, visto que a incerteza conduz os indivíduos a tomarem certas decisões racionais no nível individual (como a de reter moeda) que, no agregado, geram resultados negativos do ponto de vista social (desemprego involuntário). Destarte,

Para enfrentar a incerteza e a ignorância dever-se-ia pensar em um amplo conjunto de ações concentradas, a fim de sustentar a demanda e reduzir os riscos da atividade econômica percebidos pelos indivíduos. Se bem-sucedidas, essas políticas elevariam os preços de demanda dos bens de capital e estimulariam sua acumulação. (Carvalho, 1999, p. 280)

As implicações para a política econômica, deduzidas a partir do pensamento keynesiano, não apontam para um Estado interventor na dimensão 
da determinação do investimento privado. Apontam para um Estado cujos investimentos a ele pertinentes contribuam para a formação de um ambiente de confiança no futuro da economia. Medidas que favoreçam o otimismo dos empresários são bem-vindas, pois, ao melhorarem as expectativas de curto prazo dos empresários, têm impacto positivo sobre o cálculo das rendas esperadas e, logo, sobre o montante de investimentos desejado pelas empresas privadas. ${ }^{18}$

Portanto, o conteúdo teórico da Teoria Geral não invoca a formação de um Estado centralizador das decisões individuais, mas de um Estado indutor do emprego. Em geral, faz-se necessária a formação de instituições que sejam reguladoras e estimuladoras, no sentido de (a) estimular a demanda efetiva quando o setor privado apresente uma propensão a produzir escassez da mesma e (b) reduzir a demanda efetiva sempre que o nível de pleno emprego for ultrapassado, o que, caso contrário, permitiria impactos significativos sobre a estrutura de custos das empresas e sobre o nível de preços (Davidson, 1996, p. 503).

\section{O ROMPIMENTO COM A LEI DE SAY: IMPLICAÇÕES METODOLÓGICAS E DINÂMICAS}

A noção de equilíbrio empregada na análise neoclássica, conforme visto acima, está associada a uma realidade predeterminada (ergodicidade) e à convergência para um estado ideal: o pleno emprego dos fatores. Neste caso, há as seguintes implicações:

(i) A influência do determinismo metodológico (ligado à física clássica) é clara, uma vez que a natureza do sistema econômico é concebida de maneira determinística ${ }^{19}$ e estável (Vercelli, 1994).

(ii) O tempo é tido como reversível, no sentido de que as condições necessárias à convergência do sistema (para o pleno emprego) são inflexíveis. Logo, torna-se possível reproduzir com exatidão os fenômenos observados e o sistema não apresenta mudanças qualitativas (Carvalho, 1984).

(iii) As flutuações econômicas são explicadas a partir de choques exógenos, os quais, por sua vez, são eliminados via mecanismos reguladores endógenos (Herscovici, 2002a). 
Por outro lado, os conceitos de incerteza e de propriedades essenciais da moeda, lançados pela Teoria Geral e enfatizados pelos pós-keynesianos, fazem surgir implicações distintas:

(a) A natureza do sistema econômico, sua trajetória, não é suscetível de predeterminação: rompe-se com o mecanicismo, dando-se espaço ao desequilíbrio e à instabilidade (Vercelli, 1994).

(b) O tempo é histórico e irreversível, pois as decisões dos agentes, tais como as de investimento, são capazes de alterar o contexto em que foram feitas (as condições iniciais são variáveis) e mudanças qualitativas no sistema são possíveis (Carvalho, 1984).

(c) Flutuações e ciclos econômicos têm origem endógena. $\mathrm{O}$ sistema não garante uma auto-regulação perfeita. $\mathrm{Na}$ presença de possíveis desequilíbrios permanentes, reguladores exógenos são necessários a fim de permitir a reprodução do sistema (Herscovici, 2002a).

Na visão de Vercelli (1994), os elementos teóricos fornecidos por Keynes permitem a introdução de uma dinâmica pós-clássica nas ciências econômicas. A dinâmica clássica estaria associada aos desenvolvimentos da mecânica newtoniana e seria responsável, em grande parte, pelo teor reducionista da economia no século XIX e início do século XX; a dinâmica pós-clássica, por sua vez, seria desenvolvida a partir da termodinâmica, ${ }^{20}$ constituindo-se em instrumento necessário para a análise de sistemas complexos e instáveis. Ao conceber o sistema econômico como suscetível de incerteza, e, portanto, de natureza complexa, Keynes (1936) rompe com o reducionismo no âmbito da economia e dá margem à utilização da dinâmica não linear (pós-clássica) na análise dos fenômenos econômicos.

\section{CONSIDERAÇÕES FINAIS}

O equilíbrio estável na teoria neoclássica corresponde a uma situação ideal: o pleno emprego dos fatores de produção. As hipóteses da ergodicidade e da neutralidade da moeda permitem o pleno funcionamento da Lei de Say. Todavia, ao se introduzirem a incerteza e as propriedades essenciais da moeda no sistema econômico, a igualdade constante entre renda e gastos correntes, proposta por aquela lei, torna-se inviável. A partir disso, a busca de segurança na moeda, em uma realidade não ergódica, faz com que o equilíbrio 
(não predeterminado) possa ocorrer fora do pleno emprego. Políticas públicas surgem como um elemento necessário para melhorar a performance da economia, via regulação da demanda efetiva. Em outras palavras, as instituições são necessárias à reprodução do sistema capitalista uma vez que suas forças endógenas não lhe garantem uma regulação sustentável, e muito menos o pleno emprego.

\section{NOTAS}

1. Na Teoria Geral (1936), Keynes utiliza o termo "clássicos" para descrever os representantes da teoria contra a qual ele escrevia. Neste artigo, utilizo o termo "neoclássicos". A teoria neoclássica, para efeitos deste trabalho, está baseada, principalmente, no pensamento de Marshal, Edgeworth e Pigou. Pode-se também incluir neste conjunto Menger e Jevons, representantes da corrente marginalista. Tenho preferência pelo termo "neoclássicos", em detrimento do termo "clássicos", no sentido de deixar claro que o presente artigo não remete suas críticas gerais às teorias de Smith e Ricardo, salvo sob casos especiais, sendo esses casos explicitados em seu devido momento.

2. A Lei de Say também ocupava importante papel no pensamento dos economistas clássicos. Para David Ricardo, por exemplo, "Say demonstrou de modo mais satisfatório que não há nenhum montante de capital que não possa ser investido num país porque a procura só pode ser limitada pela produção. Ninguém produz se não tiver a intenção de consumir ou de vender e ninguém vende se não tiver a intenção de comprar (...) a moeda é só o meio pelo qual se efetua a troca" (Ricardo, 1821, p. 334-336).

3. Na teoria neoclássica, existe a possibilidade de uma diferença entre poupança e investimento, caracterizando um desequilíbrio provisório. $\mathrm{Na}$ economia de Keynes, entretanto, a poupança é um simples resíduo da renda, o excedente sobre o que foi gasto com bens de consumo. Em Keynes, a priori, poupança sempre equivale ao investimento. À frente, ver-se-á como pode haver uma diferença provisória entre ambos, embora não seja a taxa de juros a responsável pela igualação entre as duas variáveis no pensamento keynesiano.

4. A ergodicidade, todavia, não exclui a ocorrência de erros. Em uma perspectiva novoclássica, pelo uso de expectativas racionais, os erros de previsão podem ocorrer, muito embora não de forma sistemática. Não obstante isso, na média, os agentes sempre acertam.

5. A ergodicidade também implica: (a) a freqüência relativa de um evento $X$ é a mesma em qualquer ponto do tempo e (b) não há mudanças qualitativas do sistema (Herscovici, 2003).

6. Trata-se de uma escolha intertemporal do consumo. Apenas ex-ante pode haver algum desemprego, de natureza provisória. Todavia, ex-post, o emprego agregado é mantido, tendo ocorrido apenas uma redistribuição dos trabalhadores entre os setores de bens de consumo e de investimento. 
7. Embora pareça de difícil entendimento este argumento, o processo é idêntico ao usado para o estudo microeconômico das decisões da firma e do consumidor.

8. O fato de certas decisões de gastos, tais como as de investimento, não serem determinadas pelos resultados correntes, mas sim pelas expectativas acerca dos resultados de longo prazo, é necessário para uma refutação da teoria neoclássica. Todavia, não há ainda consenso sobre a forma pela qual essas expectativas são formadas. Apesar de Davidson (1999) defender uma formação exógena das expectativas de longo prazo, Herscovici (2002a), p. ex., defende a tese de que essas expectativas têm formação endógena, ao menos em parte, como requisito para a construção de uma abordagem coerente das flutuações econômicas.

9. A explicação completa apenas será possível com a análise das propriedades essenciais da moeda, feita a seguir.

10. Nesse artigo em particular, Dequech (2001) usa o termo "incerteza fundamental" no mesmo sentido em que usa o termo incerteza, "num sentido forte"(1999).

11. Ao contrário do que acontece na análise neoclássica, onde as flutuações econômicas têm causa exógena e caráter estritamente temporário.

12. Keynes supõe a existência de rendimentos decrescentes na indústria. Assim, com o crescimento no estoque de capital, há uma tendência de redução da eficiência marginal do capital, à medida que os custos de produção dos bens de capital aumentam e os lucros esperados são menores (Keynes, op. cit., p. 244). Em David Ricardo, por outro lado, não se supõe a existência de rendimentos decrescentes, a menos que haja uma elevação dos salários dos trabalhadores. Contudo, Ricardo admite a ocorrência da Lei de Say, mostrando que não há limites para a procura, exceto na produção. A moeda é tida como um simples meio pelo qual as trocas reais são realizadas (Ricardo, 1821, p. 333-336). Assim, Ricardo também era adepto da Lei de Say e não acreditava na possibilidade de crises de superprodução de caráter duradouro. Para ele, no agregado, a oferta gera sua procura.

13. É possível apresentar esta formalização mediante defasagens temporais, de modo que a eficiência marginal no período $t$ seja inversamente relacionada com o diferencial da eficiência marginal no período $t-1$ em relação à taxa de juros (constante) (ver Herscovici, 2003).

14. Caso se queira acrescentar a variação do retorno de cada bem em ralação ao valor da moeda, acrescenta-se o termo " $a$ ", que pode ser positivo ou negativo. A soma completa fica $[(q-c)+1+a]$ para todos os bens, com exceção, obviamente, da moeda, o próprio padrão de referência, cuja "soma" completa reduz-se a “ $P$ ”, pois $(q-c)$ para ela é nulo.

15. Para que a moeda tenha esta propriedade é necessário que ela não seja uma mercadoria produzível pelo setor privado. Na época histórica sob vigência do padrão ouro, portanto, a moeda mercadoria não possuía uma elasticidade de produção tão desprezível como a que se verificava nos anos 30. Todavia, Marx já definira a moeda como uma relação social, um equivalente geral, cujas funções podem ser desempenhadas por ativos não produzíveis pelo trabalho, muito embora ela sempre expresse o valor do trabalho. Ademais, para efeitos deste artigo, define-se moeda como um ativo não produzível pela indústria. 
16. Ao se referir a equilíbrio estável, não se defende uma interpretação estática do pensamento de Keynes. A meu ver, o conceito de equilíbrio estável não exclui a dinâmica econômica. O ciclo econômico da renda, quando apresentasse uma amplitude constante ao longo do tempo, caracterizaria um equilíbrio estável. Isto não está em contradição com a Teoria Geral.

17. Cf. Ferrari (2001).

18. Isto requer a hipótese de que as expectativas de longo prazo (relacionadas ao aumento da capacidade produtiva, i. e., investimento) não são totalmente exógenas, sendo em algum grau determinadas pelas expectativas de curto prazo (relacionadas à produção e ao emprego, dada a capacidade corrente). Assim, um aquecimento induzido e persistente da produção faz com que os empresários elevem, em alguma medida, o montante de investimentos planejados.

19. A análise neoclássica é estritamente determinística, pois não permite erros aleatórios por parte dos agentes na inferência de suas variáveis relevantes. Os modelos novo-clássicos, por sua vez, embora também concebam a ergodicidade, pois vêem a realidade econômica como sendo predeterminada, têm uma metodologia estocástica (não determinística), porque aceitam a existência de erros aleatórios. Todavia, os erros aleatórios de previsão dos agentes são eliminados via hipótese de expectativas racionais, fazendo o sistema convergir para as taxas naturais ou potenciais, ao menos a longo prazo (Ferrari, 2001).

20. A termodinâmica representa uma ruptura de paradigma no âmbito da física. Ela possibilita a análise de sistemas instáveis e complexos. "O sistema dir-se-á instável se uma análise mostrar que algumas flutuações, em vez de regredirem, se podem amplificar, invadir todo o sistema, fazendo-o evoluir para um novo regime de funcionamento qualitativamente diferente" (Prigogine, 1991, p. 112).

\section{REFERÊNCIAS BIBLIOGRÁFICAS}

CARVALHO, F. C. (1984) “On the concept of time in Shacklean and Sraffian economics". Journal of Post-Keynesian Economics, Winter 1984, v. VI, n. 2, Cambridge.

(1999) "Políticas econômicas para economias monetárias". In: J. Sicsú, Macroeconomia moderna: Keynes e a economia contemporânea. Rio de Janeiro: Campus.

DAVIDSON, P. (1996). "Reality and economic theory". Journal of Post Keynesian Economics, Summer 1996, v. 18, n. 4.

(1999) "Colocando as evidências em ordem: macroeconomia de Keynes versus velho e novo keynesianismo”. In: J. Sicsú, Macroeconomia moderna: Keynes e a economia contemporânea. Rio de Janeiro: Campus.

DEQUECH, D. (1999) “Incerteza num sentido forte: significado e fontes”. In: J. Sicsú, Macroeconomia moderna: Keynes e a economia contemporânea. Rio de Janeiro: Campus.

- (2001) "Bounded rationality, institutions and uncertainty". Texto para Discussão. IE/Unicamp, n. 100, jun. 2001. 
DOW, S. (1985) “Macroeconomic Thought: a methodological approach". Cambridge: Basil Blackwell.

FEIJÓ, C. A. (1999) “Decisões empresariais em uma economia monetária de produção”. In: J. Sicsú, Macroeconomia moderna: Keynes e a economia contemporânea. Rio de Janeiro: Campus.

FERRARI, M. A. (2001) “Uma análise da macroeconomia novo-clássica”. Revista Perspectiva Econômica, n. 1, Vitória, UFES, ago.

FILHO, F., ARAÚJO, J. P. (2000) “Caos, incerteza e teoria pós-keynesiana”. Anais do V Encontro Nacional da Sociedade de Economia Política, SEP.

HAGEN, E. E. (1949) “The classical theory of the level of output and employment”. In: M. G. Mueller, Readings in Macroeconomics, 1966.

HERSCOVICI, A. (2004) “O modelo de instabilidade de Harrod: uma abordagem em termos de não-linearidade”. Textos do Grupo de Estudos em Macroeconomia (GREM). Mimeo. Vitória.

(2002a) "Dinâmica macroeconômica: uma interpretação a partir de Marx e de Keynes”. Vitória: Ediufes.

- (2002b) "Economia do desequilíbrio, preços e instituições". Ensaios (FEE), Porto Alegre, v. 23, n. 1, p. 57-76.

(2003) "Historicidade, entropia e não-linearidade: algumas aplicações possíveis na Ciência Econômica”. Anais do XXXI Encontro Nacional da Anpec, Porto Seguro, dez.

KREGEL, J. (1980) "Markets and institutions as features of a capitalistic production system". Journal of Post-keynesian Economics, Fall 1980, v. III, n. 1.

KEYNES, J. M. (1936) “A teoria geral do emprego, do juro e da moeda”. São Paulo: Atlas, 1982 (1. ed. em inglês, 1936).

MEIRELLES, A. J. (1998) “Moeda e produção: uma análise da polêmica pós-keynesiana sobre a endogenia monetária”. São Paulo: Fapesp.

PRIGOGINE, I. (1991) “A nova aliança: metamorfose da ciência”. Brasília: UNB, 1991.

RICARDO, D. (1821) "Princípios de economia política e de tributação". Fundação Calouste Gulbenkian: Lisboa, 1965 (traduzido da 3. ed. em inglês, 1821).

SAY, J. B. (1803) “Tratado de economia política”. São Paulo: Nova Cultural, 1986 (1. ed. em francês, 1803).

VERCELLI, A. (1994) "Por uma macroeconomia não reducionista: uma perspectiva de longo prazo”. Economia e Sociedade, Campinas (3), dez. 